\title{
Engineering Application and In-situ Monitoring Analysis of Retaining Structures of New H-section Steel Support System in Foundation Pit
}

\author{
Lei Han ${ }^{a}$, Min Sun, Hao Wang and Guo-xin Wang \\ China Construction Eighth Engineering Division Co., Ltd., Shanghai 200122, China
}

\begin{abstract}
A new H-section steel support system is introduced based on a foundation pit project in Shanghai. In-situ monitoring was carried out to measure the displacement of supporting piles. The monitoring results showed that the displacement of pile-top was closely related to the excavation depth and time. It is basically no longer developing after the foundation slab concreted finished. Horizontal displacement of the pile body increased gradually with the increase of excavation depth. The maximum horizontal displacement was about $25 \mathrm{~mm}$ and the position was about $1 \mathrm{~m}$ below the bottom of the foundation pit. Finally, the horizontal displacement of the pile body was presented as a "bow" with a small displacement at two ends and a large displacement in the middle. Compared with those at reinforced concrete support area, it showed that the deformation law and final displacement value of pile-top and pile body in the new H-section steel support area was basically the same as that of reinforced concrete support area. And all of the monitoring data were within the security range, meeting the design and code requirements. Moreover, new H-section steel support system construction period was short and the cost was low. It could effectively improve the green construction level. The conclusions obtained in this paper could be referred for other familiar projects.
\end{abstract}

\section{Introduction}

With the development of urban underground space, the number and area of foundation pit projects are increasing domestic and overseas [1-3]. In soft soil areas, the reinforced concrete support system is usually adopted in foundation pit project $[4,5]$. The reinforced concrete support construction period is long and a lot of waste concrete will be produced when it is removed along with noise and dust pollution. It not only wastes resources but also brings pollutions to the environment. Steel support systems use steel pipe or section steel as the support of foundation pit. Compared with reinforced concrete support, steel support can be reused, and it does not produce waste during application. It is in line with the engineering development idea of efficient economy and green environment protecting. Steel support systems were come into use in the 1990s in China $[6,7]$. As the traditional steel support system and construction method were easy to cause the loss of pre axial force, it was not conducive to the deformation control of foundation pit support structure [8]. So, it has not been widely used.

In this paper, a new H-section steel support system is introduced based on a foundation pit project in Shanghai. In-situ monitoring was carried out to measure the displacement of supporting piles. The time history of displacement of pile-top and pile body during excavation were obtained. Through comparative analysis with

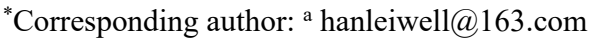

reinforced concrete support, the feasibility of the application of the new H-section support system in foundation pit project was verified. The conclusions obtained in this paper could provide guidance and reference for other similar projects.

\section{Project profile}

The schematic illustration of this foundation pit project was shown in Figure 1. The perimeter of the foundation pit was about $630 \mathrm{~m}$. The excavation area and depth were about $20,000 \mathrm{~m}^{2}$ and $8.70 \sim 9.25 \mathrm{~m}$. There were two floors of basement. In the south side of this foundation pit, it was the built-up structures of one floor basement of phase I. The rest were planned roads. The safety level of foundation pit was two and the environmental protection level was three.

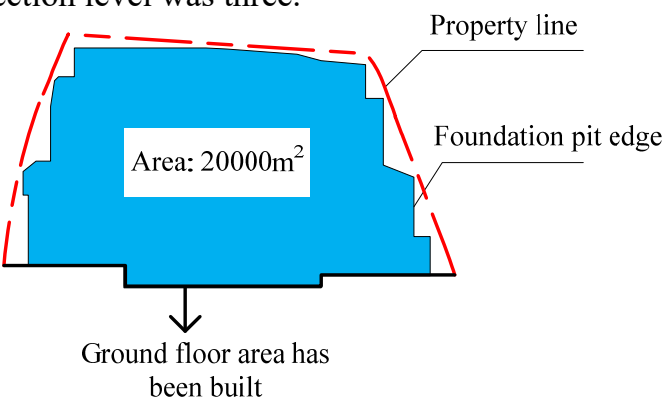

Figure 1. Schematic illustration of foundation pit project 


\section{Introduction of new $\mathrm{H}-$ section support system}

The structural diagram of the new H-section support system is shown in Figure 2. It consists of $\mathrm{H}$-section steel support, steel enclosing purlin, octagon brace, connecting rod, vertical column and jack. Steel support, steel enclosing purlin, octagon brace and connecting rod are all modular $\mathrm{H}$-section steel components. And steel components are bolted together. Vertical columns generally are H-section steel columns, lattice columns or round steel pipe columns. Envelop enclosure generally is bored pile, SMW pile or steel sheet pile. Single Hsection steel is connected by a connecting rod to enhance the integrity of new H-section steel support system. The jack is bolted in the $\mathrm{H}$-section support. Apply preloading force before excavation to control the deformation of foundation pit support system. It will not been taken out before the end of foundation pit project to maintain the support force. New H-section steel support system is assemblage. It can be assembly arbitrarily to enhance the integrity of new H-section steel support system.

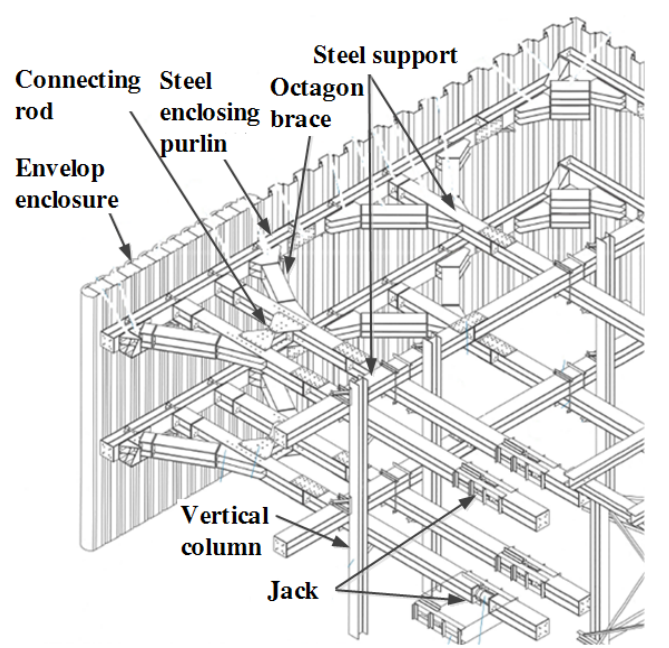

Figure 2. Structural diagram of the new H-section support system

\section{Design of foundation pit support system}

This foundation pit is supported by vertical envelop enclosure with bored piles and SMW piles and two horizontal internal supports. The first horizontal supports are all reinforced concrete supports as shown in Figure 3 and the second horizontal supports are reinforced concrete supports combined with new $\mathrm{H}$-section steel supports as shown in Figure 4. The length and interval of new H-section steel support are $45 \mathrm{~m}$ and $12.5 \mathrm{~m}$, respectively. And the type of section steel is $\mathrm{H} 400 \times 400 \times 13 \times 21$. The section size and supporting height of reinforced concrete supports are shown in Table 1. A photograph of foundation pit support system taken after assembly is shown in Figure 5.

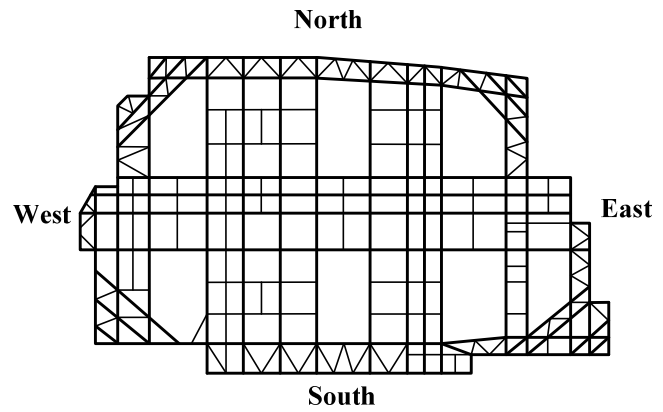

Figure 3. First horizontal support system.

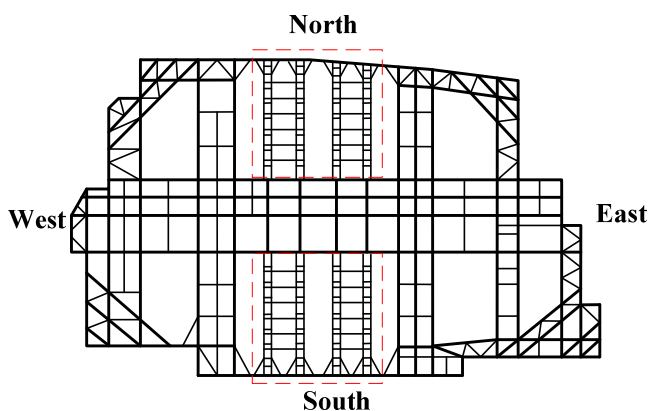

Figure 4. Second horizontal support system.

Table 1. Section size and supporting height of supports

\begin{tabular}{|c|c|c|c|c|}
\hline $\begin{array}{c}\text { Horizontal } \\
\text { support }\end{array}$ & $\begin{array}{c}\text { Depth } \\
(\mathrm{m})\end{array}$ & $\begin{array}{c}\text { Enclosing } \\
\text { purlin } \\
(\mathrm{mm} \times \mathrm{mm})\end{array}$ & $\begin{array}{c}\text { Main } \\
\text { support } \\
(\mathrm{mm} \times \mathrm{mm})\end{array}$ & $\begin{array}{c}\text { Sub } \\
\text { support } \\
(\mathrm{mm} \times \mathrm{mm})\end{array}$ \\
\hline First layer & -1.200 & $1200 \times 800$ & $800 \times 800$ & $600 \times 800$ \\
\hline $\begin{array}{c}\text { Second } \\
\text { layer }\end{array}$ & -5.150 & $1300 \times 900$ & $900 \times 900$ & $700 \times 900$ \\
\hline
\end{tabular}

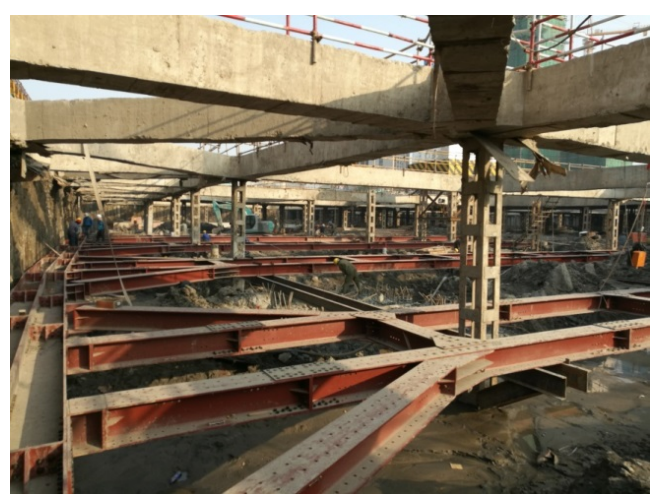

Figure 5. Photograph of foundation pit support system.

\section{Layout of in-situ monitoring points}

In order to obtain the deformation rule of the envelop enclosure in the area of new H-section steel support system, and make a comparison with the reinforced concrete support system. In-situ monitoring was carried out to measure the displacement of supporting piles. Layout of in-situ monitoring points was shown in Figure 6. Because this paper mainly studies the new H-section steel support system, so only the monitoring points of south and north sides of the foundation pit are listed. W1 to $\mathrm{W} 8$ and $\mathrm{W} 16$ to $\mathrm{W} 24$ are displacement monitoring points of pile-top. $\mathrm{C} 1$ to $\mathrm{C} 4$ and $\mathrm{C} 7-\mathrm{C} 10$ are horizontal displacement monitoring points of the pile body. Due to 
space limitations, only the monitoring results of north side of the foundation are analysed in this paper.

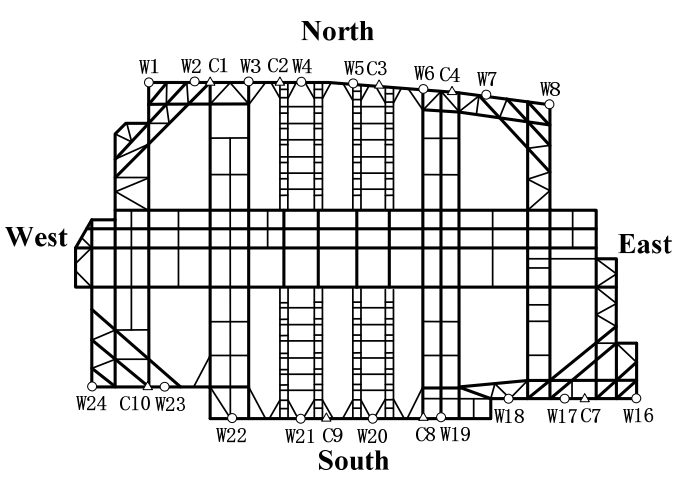

Figure 6. Layout of monitoring points of the foundation pit.

\section{Monitoring results and analysis}

In order to facilitate the analysis and comparison of monitoring results, the excavation stage of the foundation pit project are provided as follows:

(1) 2016.10 .30 to 2016.11 .25 , construction of the first reinforced concrete support;

(2) 2016.11.25 to 2016.12.06, excavation of the foundation pit of the first floor underground;

(3) 2016.12.06 to 2016.12.31, construction of the second reinforced concrete support and new H-section steel support;

(4) 2016.12.31 to 2017.01.20, excavation of the foundation pit of the second floor underground;

(5) 2017.01.20, foundation slab concreted finished.

\subsection{Analysis of the displacement monitoring results of pile-top}

Vertical displacement and horizontal displacement deformation rule of pile-top along with the excavation of foundation pit excavation as shown in Figure 7 and Figure 8, respectively. Positive values indicate uplift of pile-top or displacement to the outside of foundation pit. Negative values indicate settlement of pile-top or displacement into the foundation pit. From Figure 7 and 8 , we can find that the deformation of pile-top was closely related to the excavation depth and time. During the construction of first and second horizontal supports, there was little vertical displacement of pile-top and the maximum horizontal displacement was $5 \mathrm{~mm}$. During the excavation of the first and second floors underground, obvious displacement was occurred at the top of piles of all monitoring points. The maximum vertical and horizontal displacements of pile-top were $25 \mathrm{~mm}$ and 27 $\mathrm{mm}$, respectively. It is basically no longer developing after the foundation slab concreted finished. Therefore, in the process of foundation pit excavation, in order to control the deformation and ensure the safety of foundation pit, the excavation time of foundation pit should be shortened as far as possible and the foundation slab should be concreted as soon as possible.

As shown in Figure 6, W4 and W5 are the displacement monitoring points of pile-up in new $\mathrm{H}$ section steel support area. W1 to W3 and W6 to W8 are the displacement monitoring points of pile-up in reinforced concrete support area. In the following, supporting effects of new $\mathrm{H}$-section steel support and reinforced concrete support will be compared and analyzed. To ignore the effects of the boundary effect, the data of corner points (W1 and W8) of the foundation pit are not given in the Figures.

From Figure 7 and Figure 8, we can find that deformation rule and the final displacement of each monitoring point is basically the same. The final vertical displacement of pile-top finally stabilizes between $20 \mathrm{~mm}$ and $25 \mathrm{~mm}$ and the final horizontal displacement of piletop finally stabilizes between $20 \mathrm{~mm}$ and $27 \mathrm{~mm}$. That is to say, the supporting effect of the new H-section steel support is basically the same as that of reinforced concrete support. And the maximum vertical and horizontal displacements are $25 \mathrm{~mm}$ and $27 \mathrm{~mm}$, respectively. And monitoring data were within the security range, meeting the design and code requirements. So, the new $\mathrm{H}$-section steel support proposed in this study is safe and can be used as the support system during the construction of foundation pits.

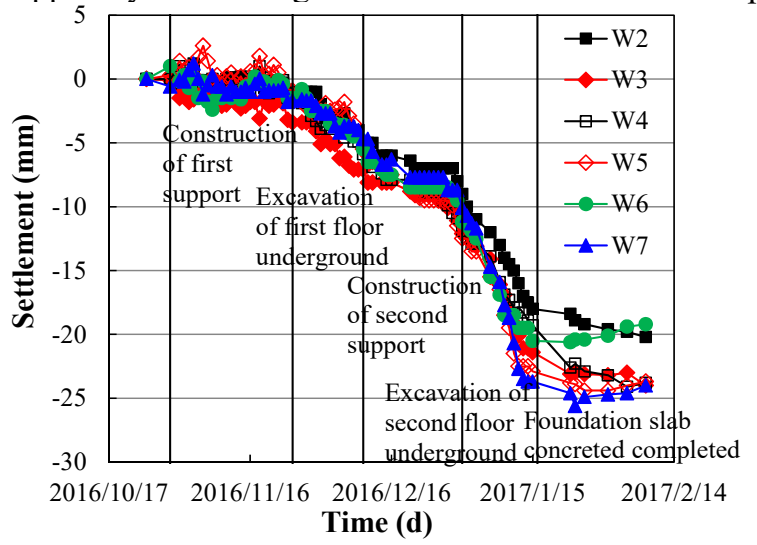

Figure 7. Time history of vertical displacement of pile-up

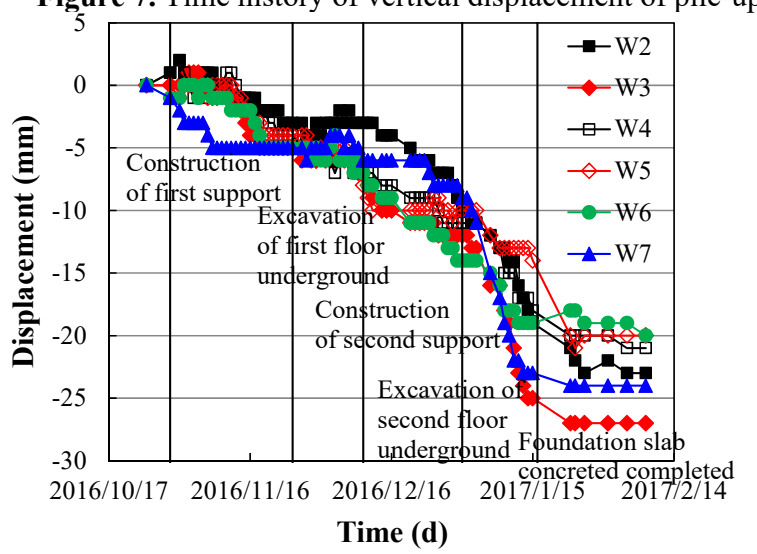

Figure 8. Time history of horizontal displacement of pile-up

\subsection{Analysis of horizontal displacement monitoring results of the pile body}

Horizontal displacements at different depths of the pile body in areas of new H-section steel support and reinforced concrete support are shown in Figure 9 and Figure 10. Positive values indicate displacement to the outside of foundation pit. Negative values indicate 
displacement into the foundation pit. We can find that the displacement of the pile body is also closely related to the excavation depth and time. Before the excavation of the second floor underground on 2016.12.31, the maximum horizontal displacement was $12 \mathrm{~mm}$, which occurred about $5 \mathrm{~m}$ away from the ground surface, i.e. current excavation depth of foundation pit. With the excavation of the second floor underground, horizontal displacement of the pile body increased gradually. The position of maximum horizontal displacement also gradually moves down. Finally, the horizontal displacement of the pile body is presented as a "bow" with a small displacement at two ends and a large displacement in the middle. The maximum horizontal displacement was about $25 \mathrm{~mm}$ and the position was about $1 \mathrm{~m}$ below the bottom of the foundation pit.

Comparing the horizontal displacement of $\mathrm{C} 2$ in the area of new H-section steel support and $\mathrm{C} 1$ in the area of reinforced concrete support, we can find that the deformation rule and maximum horizontal displacement of the pile body at different depths is basically the same. That is to say, the supporting effect of the new H-section steel support is basically the same as that of reinforced concrete support. And the maximum horizontal displacement is $25 \mathrm{~mm}$, which is within the security range, meeting the design and code requirements. So, the new $\mathrm{H}$-section steel support proposed in this study is safe and meets the requirements of engineering safety and deformation.

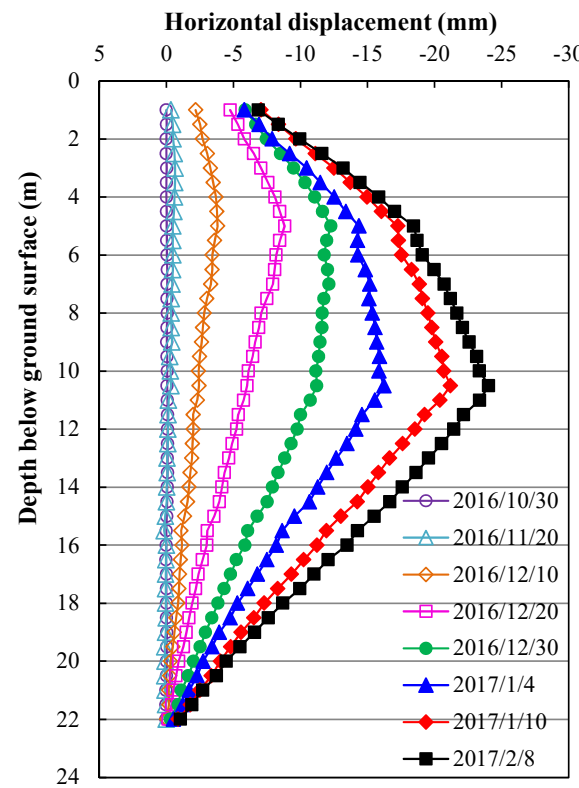

Figure 9. Horizontal displacement of the pile body of $\mathrm{C} 2$ point in the area of new H-section steel support

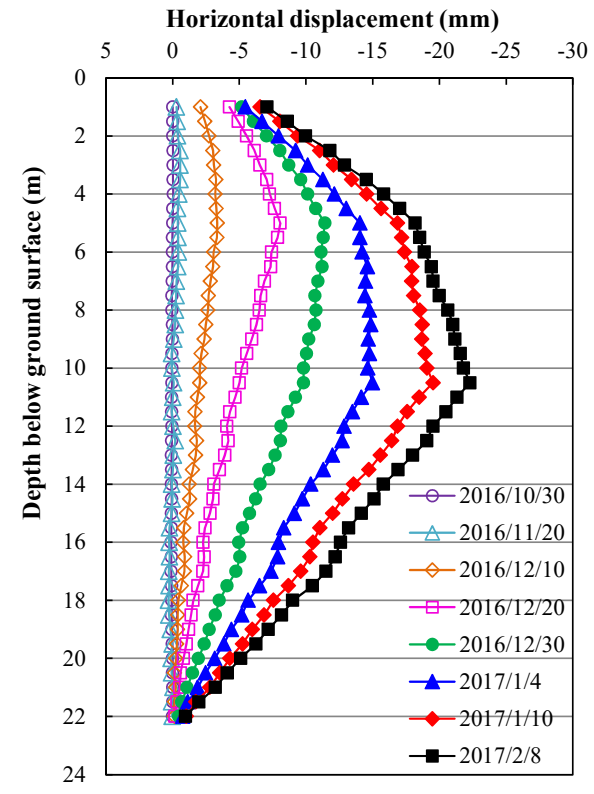

Figure 10. Horizontal displacement of the pile body of $\mathrm{C} 1$ point in the area of reinforced concrete support

\section{Conclusions}

A new $\mathrm{H}$-section steel support system was introduced based on a foundation pit project in Shanghai in this study. In-situ monitoring was carried out to measure the displacement of supporting piles. Comparative analysis between new $\mathrm{H}$-section steel support and reinforced concrete support was also conducted. We can daw conclusions as follows:

(1) The displacement of pile-top was closely related to the excavation depth and time of foundation pit. Excavation of foundation pit can cause obvious displacement of pile-up. It is basically no longer developing after the foundation slab concreted finished. In the process of foundation pit excavation, the excavation time of foundation pit should be shortened as far as possible and the foundation slab should be concreted as soon as possible to control the deformation and ensure the safety of foundation pit.

(2) With the excavation of the foundation pit, horizontal displacement of pile body increased gradually and the position of maximum horizontal displacement also gradually moves down. The maximum horizontal displacement was about $25 \mathrm{~mm}$ and the position was about $1 \mathrm{~m}$ below the bottom of the foundation pit. Finally, the horizontal displacement of the pile body is presented as a "bow" with a small displacement at two ends and a large displacement in the middle.

(3) The deformation rule and final displacement of the pile-up and the pile body is basically the same and all are within the security range, meeting the design and code requirements. So, the new H-section steel support proposed in this study is safe and meets the requirements of engineering safety and deformation. Moreover, new $\mathrm{H}$-section steel support system construction period was short and the cost was low. It could effectively improve the green construction level. The conclusions obtained in this paper could be referred for other familiar projects. 


\section{References}

1. M.G. Li, Z.J. Zhang, J.J. Chen, J.H. Wang, A.J. $\mathrm{Xu}$, Zoned and staged construction of an underground complex in Shanghai soft clay. Tunnelling and Underground Space Technology. 67 (2017)

2. J.S. Park, Y.S. Joo, N.K. Kim, New Earth Retention System with Prestressed Wales in an Urban Excavation. Journal of Geotechnical and Geoenvironmental Engineering. 135 (2009)

3. J.J. Chen, J.H. Wang, W. Fan, W.D. Wang, Behaviour of up-lift pile foundation during largescale deep excavation. Chinese Journal of Geotechnical Engineering. 31 (2009)

4. W.D. Wang, J.B. WU, S.M. Huang, Recent Progress and Characteristics of Pit Foundation in Shanghai. Chinese Journal of Underground Space and Engineering. 1 (2005)

5. Y.J. Teng, J.F. Gong, J.M. Li, State of arts of foundation engineering technology development. China Civil Engineering Journal. 45 (2012)

6. Y.T. Zhou, Q.X. Xue, Technical Measures Taken for the Reduction in Number of Horizental Braces of Large-Size Foundation Pit-Experience with Pit Enclosure of 28-storeyed Youyou Tower. Building Construction. (1994)

7. H.L. Liu, H. Shen, Deep Foundation Pit Support Technology of International Trade Center Phase II. Construction Technology. 27 (1998)

8. H.W. Li, G.X. Wang. Causes and Suggestion on Deep Foundation Excavation Accident in Some Metro Station. Construction Technology. 39 (2010) 